\title{
Laurence Guyon, Cendrars en énigme. Modèles mystiques, écritures poétiques
}

\section{Elisa Bricco}

\section{(2) OpenEdition}

1 Journals

\section{Edizione digitale}

URL: http://journals.openedition.org/studifrancesi/8063

DOI: 10.4000/studifrancesi.8063

ISSN: 2421-5856

\section{Editore}

Rosenberg \& Sellier

\section{Edizione cartacea}

Data di pubblicazione: 1 juillet 2009

Paginazione: 437

ISSN: 0039-2944

\section{Notizia bibliografica digitale}

Elisa Bricco, «Laurence Guyon, Cendrars en énigme. Modèles mystiques, écritures poétiques», Studi

Francesi [Online], 158 (LIII | II) | 2009, online dal 30 novembre 2015, consultato il 13 janvier 2021. URL: http://journals.openedition.org/studifrancesi/8063 ; DOI: https://doi.org/10.4000/studifrancesi.8063

Questo documento è stato generato automaticamente il 13 janvier 2021.

\section{(c) (i) $\odot$}

Studi Francesi è distribuita con Licenza Creative Commons Attribuzione - Non commerciale - Non opere derivate 4.0 Internazionale. 


\title{
Laurence Guyon, Cendrars en énigme. Modèles mystiques, écritures poétiques
}

\author{
Elisa Bricco
}

\section{NOTIZIA}

LAURENCE GUYON, Cendrars en énigme. Modèles mystiques, écritures poétiques, Paris, Champion, 2007, pp. 228.

1 Il saggio presenta un'attenta e molto documentata lettura dei cinque volumi autobiografici che costituiscono i «Souvenirs» di Blaise Cendrars. L'Homme foudroyé, La Main coupée, Le Lotissement du ciel, Bourlinguer e La Banlieue de Paris sono testi in cui l'immagine dell'autore subisce una parcellizzazione caleidoscopica che dimostra la difficoltà a raccontarsi. Inoltre, spesso il gioco tra l'affabulazione e la realtà lascia il lettore indeciso sulla corretta interpretazione dei testi, per la grande indeterminazione che li costituisce e al tempo stesso per la presenza di una massa eterogenea di spunti letterari, filosofici, culturali, ecc. Tra le possibili piste di lettura e di interpretazione, l'A. sceglie di fare luce sulle influenze religiose e filosofiche mostrando efficacemente la presenza di un importante sostrato di riferimenti e modelli testuali che possono essere ricondotti alle sacre scritture e alla mistica cristiana.

2 Il volume è diviso in tre parti che illustrano il percorso di ricerca personale di Cendrars. Nella prima parte, è mostrata la presa di distanza dalla religione e dalle pratiche religiose che subiscono il trattamento derisorio dello scrittore. Così scopriamo che $\mathrm{i}$ ritratti agiografici, i racconti edificanti, le narrazioni di conversioni di uomini eccellenti sono modelli testuali che lo scrittore adotta per criticarli dall'interno, considerandoli strumenti per raccogliere proseliti e per trasmettere false ideologie. Nei «Souvenirs» si legge dunque un attacco ben preciso nei confronti delle sacre scritture e in particolare della Bibbia, che viene citata nei testi in maniera così diretta che viene negato ogni spazio per una possibile esegesi. Allo stesso modo lo scrittore si appropria, scardinandoli, degli schemi della preghiera, della liturgia e dell'esame di coscienza 
considerati uniche forme possibili per stabilire un dialogo con Dio. Attraverso la messa in parallelo delle citazioni tratte dai testi cendrarsiani con gli elementi della letteratura religiosa, l'A. perviene a illustrare la forte messa in discussione della possibilità che questi modelli testuali hanno di stabilire verità e di fornire risposte adeguate alle interrogazioni dell'uomo moderno, confrontato in particolare con la realtà del secondo conflitto mondiale. La seconda e la terza parte sono incentrate sullo studio del rapporto tra le problematiche e le strategie scritturali e la scrittura autobiografica. Infatti, attraverso l'adozione degli schemi scritturali e dei topoi del discorso religioso (la posizione dell'eremita, l'impossibilità di spiegare razionalmente i misteri) Cendrars intendeva mettersi in primo piano e significare il proprio profondo smarrimento di fronte al ritorno ciclico del male assoluto. L'autobiografia diventa così uno strumento di ricerca personale e metafisica, un tentativo di ricostruzione di sé che non può essere che frammentario e lacunoso, proprio perché la ricerca è sempre in atto. 